\title{
Modern patterns of spatial distribution of the main soil parameters: case study of the Republic of Tatarstan, Russia
}

\author{
Artur Gafurov ${ }^{1,2}$ and Aidar Sharifullin ${ }^{2}$ \\ ${ }^{1}$ OpenLab Cosmoecology, Kazan Federal University, Kazan, 420008, Russia \\ ${ }^{2}$ Department of Landscape Ecology, Kazan Federal University, Kazan, 420008, Russia
}

Correspondence: Artur Gafurov (gafurov.kfu@gmail.com)

Published: 1 August 2019

\begin{abstract}
The territory of the Republic of Tatarstan (RT) belongs to the region with the most developed agriculture in Russia and the Middle Volga region. However, the formation of a system of accurate farming in the Republic is just beginning. To ensure precision farming, it is necessary to precisely know cropland borders, as well as the agrochemical properties of soils ( $\mathrm{pH}$, humus content, potassium and phosphorus content). The present study was carried out based on aerial images analyses of the most intensively used part of the RT both with identification of soil indicators for each of the fields. The availability of information on the spatial location of various cultivated crops makes it possible to assess the role of soil characteristics in these crops.
\end{abstract}

\section{Introduction}

Contemporary agricultural sector is aimed at reducing the cost per unit of output and increasing productivity per unit of expanded resources. "Precision agriculture" or "precision farming" described a method of agricultural monitoring which included the use of frequently updated information gathered by remote sensing satellites. Instead of plowing, sowing, and fertilizing "by eye", as was done throughout the previous history of agriculture, today farmers can accurately calculate the number of seeds, fertilizers and other resources for each plot of the field with an $1 \mathrm{~m}$ accuracy. Based on precise field map which is done through satellite and laboratory data analyses, the characteristics of each plot are identified. This is efficient way to resources use. Thus, it is possible to avoid overspending of resources where they were previously used in excess, and to increase the productivity of those parts of the field that were previously undersupplied in fertilizers, plowing or irrigation. The system of precision farming is not a strictly defined set of techniques and technical means, but rather a general concept based on the use of satellite positioning technologies (GPS), geographic information systems (GIS), accurate mapping of fields, etc. Studying soil characteristics, such as acidity, content of minerals and humus is an important task of modern agriculture. Understanding of spatial laws of these characteristics are particularly important. Without knowledge of these laws, precision farming is impossible. The aim of the work is to study the spatial regularities of the main soil parameters on the example of the agrarian developed part of the Republic of Tatarstan according to remote sensing data of the Earth. This requires solving the following tasks: collecting data on the main soil characteristics under field conditions, determining the boundaries of fields on the territory of agricultural lands of the Republic, determining the type of vegetation on the selected fields, searching for a connection between soil characteristics and natural anthropogenic factors, analyzing the identified patterns.

\section{Study area}

Tatarstan is located in the centre of the Russian Federation on the East European Plain, at the confluence of the two largest rivers - the Volga and Kama. The territory of the Republic is mostly laying within forest-steppe zone with small elevations on the right bank of the Volga and the south-east of the Republic. $90 \%$ of the territory lies at an altitude of no more than $200 \mathrm{~m}$ above sea level (Yermolaev et al., 2018b). More than 
$16 \%$ of the territory of the Republic is covered with forests consisting of mainly deciduous trees (oak, linden, birch, aspen), conifers are represented by pine and spruce. The climate is moderately continental. The soils are distinguished by a wide variety - from gray forest and podzolic in the north and west to various types of black soil in the south of the Republic (32\% of the area). Almost all the territory of the Republic is intensively used in agriculture (Usmanov et al., 2015). Crops such as peas, wheat, rye, barley, maize, oats, sunflower, colza, sugar beets and herbs are grown here.

One of the most important elements of soil fertility is their agrochemical characteristics. As a result of the stable land leaching, the area of acidic soils compared to the previous survey cycle (7-8 years) decreased by 160 thousand hectares and in 2007 was 1361.6 thousand hectares, or $39.2 \%$ of the arable land, there are 1090.4 thousand hectares - slightly acid, 241.3 thousand hectares - medium acid and 29.9 thousand hectares - strongly acid. The highest level of acidic soils in the Agryz district is $62.9 \%$, Aksubaevsky - 65.9\%, Alkeevsky - 69.4\%, Tukayevsky - $64 \%$, and Rybno-Slobodsky $-72.9 \%$. Currently, the weighted average $\mathrm{pH}$ value in the Republic is 5.6.

The progress in acidic soils reduction is limited by the ongoing use of physiologically acidic mineral fertilizers, high consumption of calcium and magnesium carbonates due to removal with the crop, as well as soil removal due to erosion.

\section{Material and methods}

To implement the system of precision farming on more than 3000 fields used in agriculture, the delineation of the boundaries based on aerial survey data was done. Aerial photography was carried out with $70 \%$ longitudinal and transverse overlapping of images, and the coordinates of the centres of the image were determined using of the GNSS receiver $(\mathrm{Ga}-$ furov, 2018). The reference error was within $0.3 \mathrm{~m}$ in height. The resolution of orthophotos obtained was 0.25 . Field work was carried out to determine the soil properties, such as acidity, humus, the content of potassium and phosphorus oxides in each field. These data were combined into a database based on which some statistical indicators were obtained (Table 1).

Type of vegetation for more than 1000 fields was determined. These fields, in the future, were used as etalons. The classification was carried out according to satellite imagery of the Sentinel-2 system according to the methodology given in article (Ivanov et al., 2017). The obtained data on the type of cultivated crop were used to analyze the dependence of soil indicators on the type of vegetation.

The classification of vegetation types was carried out using QGIS and EnMap plugin. ANOVA and MANOVA was conducted in the $\mathrm{R}$ language environment.

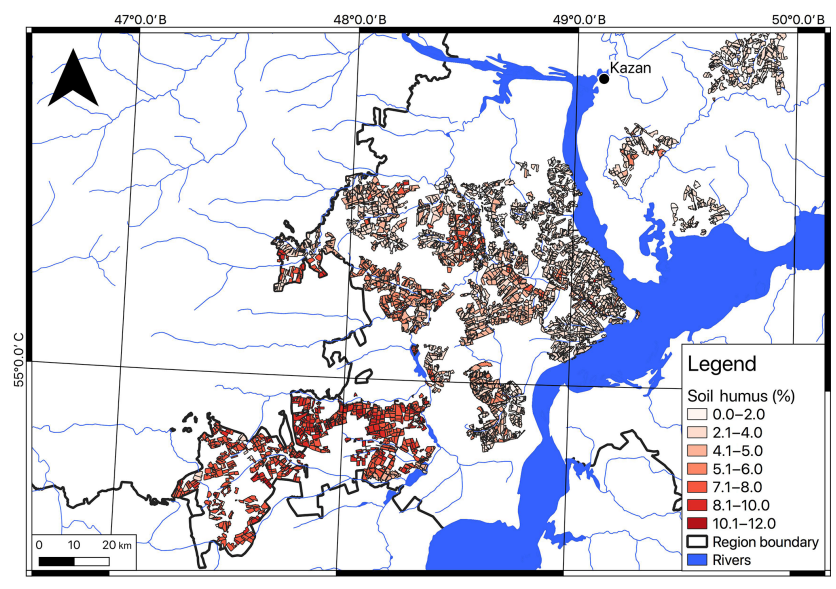

Figure 1. Distribution of humus content of soil on the example of west part of RT.

\section{Results and discussion}

Because of the research, it was found that the spatial distribution of the main plant nutrients in the study area is uneven. The obtained results indicate certain regularities in the distribution of soil fertility characteristics (Fig. 1). The nature of the distribution often depends on the topography and other physiographic conditions, but is also associated with the agrogenic load on the landscape. Around large settlements, where soils are used as arable land very intensively, there is a lack of basic plant nutrients. For the relationship between the content in the soil of nutrients for plants and the characteristics of the relief was carried out analysis of variance (ANOVA). Heights and slopes in degrees were used as an independent variable.

The results obtained suggest that there is a strong relationship between the height of the relief and $\mathrm{pH}$ values, the content of potassium and phosphorus in the soil $(p<0.001)$. Also, a strong dependence was found between the values of average slopes on the field and $\mathrm{pH}$ values, the content of potassium and humus in the soil $(p<0.001)$ (Fig. 2). With an increase in the height of the relief and slope, the acidity of the soil decreases to neutral and higher, which relates to an increase in soil washout with a steeper relief. Considering the chalky limestone deposits as a bedrock, this leads to a general leaching of the arable layer. The high influence of soil erosion on soil fertility is also confirmed by the fact that with a decrease in surface slopes the content of humus in the soil increases, which, again, is associated with a decrease in soil washability and accumulation of humus in the soil. Indicators of humus content decreases as it approaches the lower part of the river network, which indirectly may indicate low soil protection from surface runoff. A similar results are observed for the content of potassium and phosphorus oxides in the soil and are according to previous studies (Yermolaev et al., 2018a). 
Table 1. Average values of soil indicators for different parts of the Republic of Tatarstan.

\begin{tabular}{lrrrr}
\hline Soil indicator & Humus (\%) & $\mathrm{pH}$ & $\begin{array}{r}\mathrm{K}_{2} \mathrm{O} \\
\left(\mathrm{mg} \mathrm{kg}^{-1}\right)\end{array}$ & $\begin{array}{r}\mathrm{P}_{2} \mathrm{O}_{5} \\
\left(\mathrm{mg} \mathrm{kg}^{-1}\right)\end{array}$ \\
\hline West part $\left(2443^{*}\right)$ & $2.1-4.0$ & $5.1-5.5$ & $121-170$ & $151-250$ \\
North part $\left(717^{*}\right)$ & $2.1-4.0$ & $5.6-6.0$ & $81-120$ & $151-250$ \\
South part $\left(96^{*}\right)$ & $6.1-8.0$ & $5.1-5.5$ & $81-120$ & $101-150$ \\
Mean (3256*) & $2.1-4.0$ & $5.1-5.5$ & $121-170$ & $151-250$ \\
\hline
\end{tabular}

* Number of fields
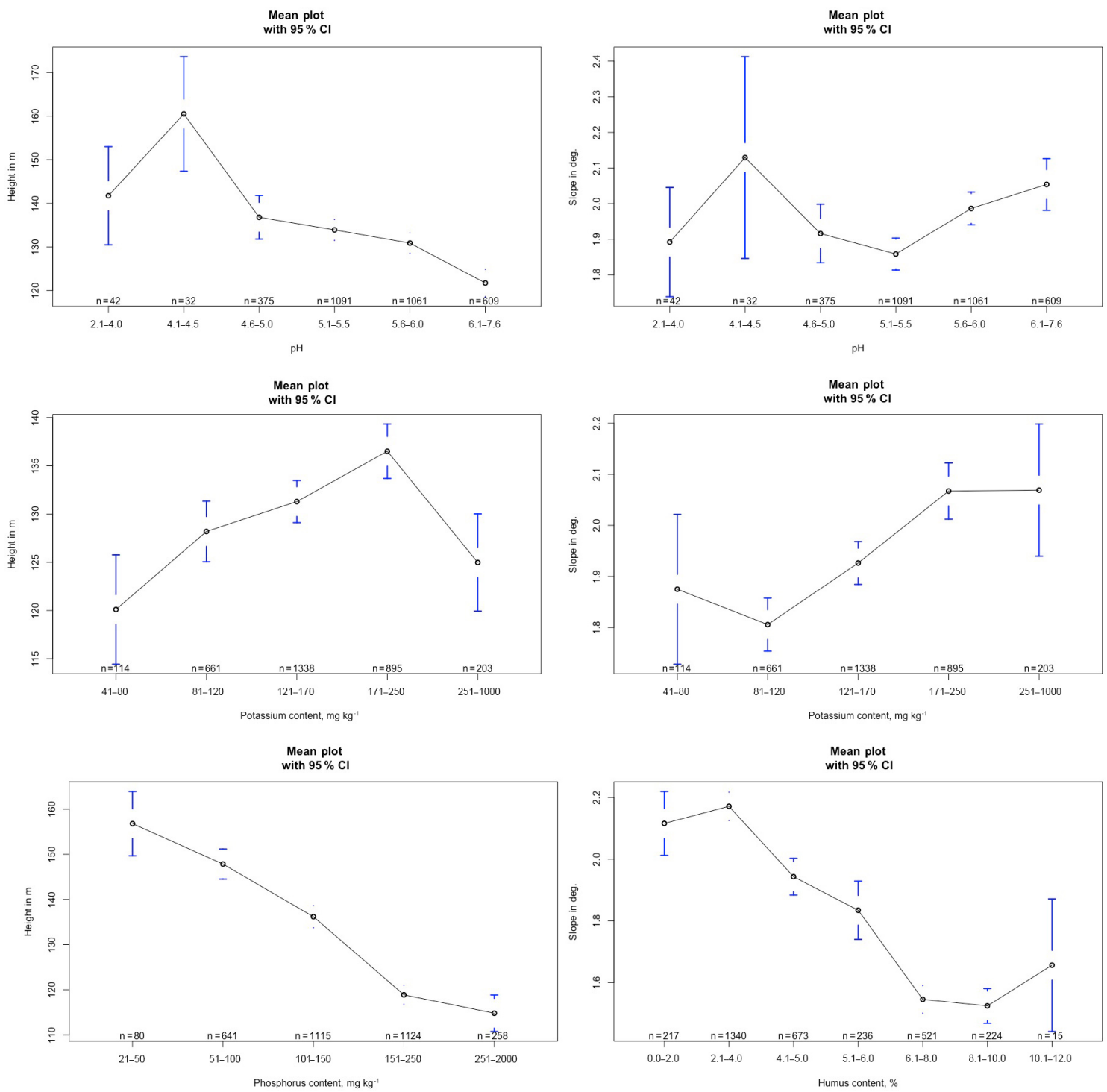

Figure 2. The ANOVA results between the content in the soil of nutrients for plants and the characteristics of the relief.

The analysis of the dependence of soil indicators on soil types showed spatial regularities characteristic of the main soil types: with the movement to the south, the soil acidity changes in the direction of its decrease, and the humus content index in the soil increases (Fig. 3). Indicators related to fertilizer application, such as the content of phosphorus and potassium in the soil, either have a weak connection with the type of soil, or have no significant relationship at all. This fact shows the supporting nature of fertilization without considering the natural features of the territory. 


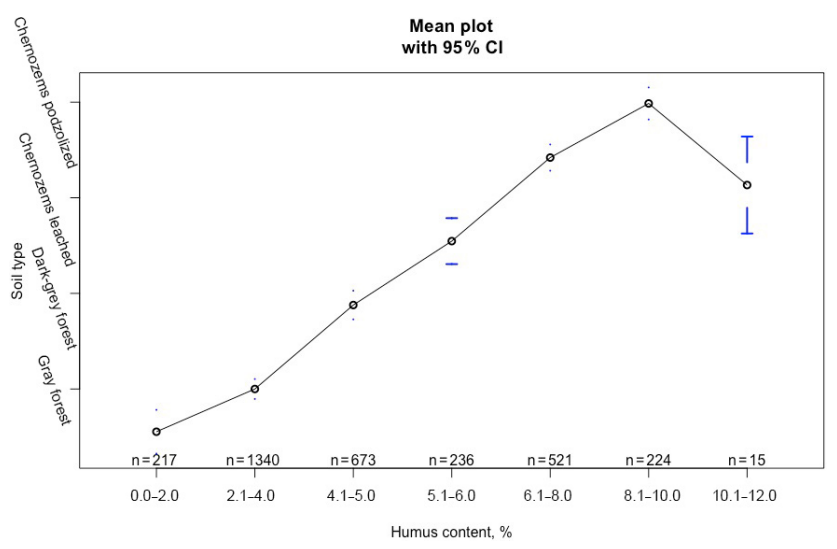

Figure 3. The ANOVA results between the soil type and the humus content.

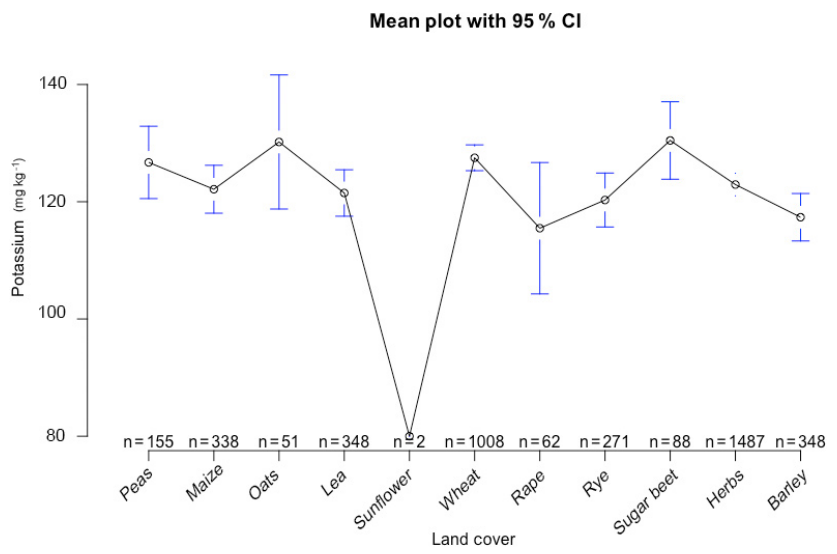

Figure 4. The ANOVA results between the culture and the potassium content in the soil.

If we consider the dependence of the content of various elements relative to each other, then no significant correlation coefficients were found.

The ANOVA (Fig. 4) and MANOVA showed a significant dependence $(p<0.05)$ of the cultivated crop on the potassium content in the soil, as well as the combined content of potassium and phosphorus. No significant correlation was found between the soil acidity index, the humus content and the type of cultivated culture.

This indicates that fertilization in the soil is not related to the yield and fertility indicators of the soil. Fertilization in this case is carried out according to the recommendations on fertilizer application from the Soviet period. Alkaline fertilizer application is also weakly related to soil acidity indicators. All this indicates the absence of so-called precision farming in most of the agricultural area of the Republic.

\section{Conclusions}

The results obtained during work suggest that precision farming in the Republic of Tatarstan is not applied. The content of nutrients in the soil is reduced due to soil erosion. Fertilizers applied to the soil are only of a supportive nature and are not related to the type of growing crop.

Data availability. Due to the fact that the data represent a commercial secret, we cannot provide public access to the results of soil analysis. The provision of data will be decided individually upon the request of interested scientists to the correspondence author.

Author contributions. The authors carried out work on field surveys with UAVs, analysis of land cover types and statistical analysis (AG), as well as collecting and analyzing soil samples in all fields and collecting information about the study area (AS).

Competing interests. The authors declare that they have no conflict of interest.

Special issue statement. This article is part of the special issue "Land use and climate change impacts on erosion and sediment transport". It is a result of the ICCE Symposium 2018 - Climate Change Impacts on Sediment Dynamics: Measurement, Modelling and Management, Moscow, Russia, 27-31 August 2018.

Acknowledgements. The study was carried out thanks to the Russian Science Foundation (collection of data on vegetation on the fields and UAV survey) and the Russian Foundation for Basic Research (collection of data on soil indicators).

Financial support. This research has been supported by the Russian Science Foundation (grant no. 19-17-00064) and the Russian Foundation for Basic Research (grant no. 18-35-00326).

\section{References}

Gafurov, A. M.: Small catchments DEM creation using Unmanned Aerial Vehicles, IOP Conf. Ser.: Earth and Env. Sci., 107, 12005, https://doi.org/10.1088/1755-1315/107/1/012005, 2018.

Ivanov, M. A., Prischepov, A. V., Golosov, V. N., Zalyaliev, R. R., Yefimov, K. V., Kondratieva, A. A., Kinyashova, A. D., and Ionova, Yu. K.: Method of croplands dynamics mapping in river basins of the European part of Russia for the period of 19852015, Sovremennye Problemy Distantsionnogo Zondirovaniya Zemli iz Kosmosa, 14, 161-171, https://doi.org/10.21046/20707401-2017-14-5-161-171, 2017.

Usmanov, B., Yermolaev, O., and Gafurov, A.: Estimates of slope erosion intensity utilizing terrestrial laser scanning, Proc. IAHS, 367, 59-65, https://doi.org/10.5194/piahs-367-59-2015, 2015. 
Yermolaev, O. P., Gafurov, A. M., and Usmanov, B. M.: Evaluation of Erosion Intensity and Dynamics Using Terrestrial Laser Scanning, Eurasian Soil Sci., 51, 814-826, https://doi.org/10.1134/s1064229318070037, 2018a.
Yermolaev, O. P., Mukharamova, S. S., Maltsev, K. A., Ivanov, M. A., Ermolaeva, P. O., Gayazov, A. I., Mozzherin, V. V., Kharchenko, S. V., Marinina, O. A., and Lisetskii, F. N.: Geographic Information System and Geoportal "River basins of the European Russia", IOP Conf. Ser.: Earth Environ. Sci., 107, 012108, https://doi.org/10.1088/1755-1315/107/1/012108, $2018 b$. 